This is an electronic reprint of the original article. This reprint may differ from the original in pagination and typographic detail.

Author(s): Alasuutari, Maarit

Title: $\quad$ Documenting Napping: The Agentic Force of Documents and Human Action

Year: $\quad 2015$

Version:

Please cite the original version:

Alasuutari, M. (2015). Documenting Napping: The Agentic Force of Documents and Human Action. Children and Society, 29(3), 219-230.

https://doi.org/10.1111/chso.12111

All material supplied via JYX is protected by copyright and other intellectual property rights, and duplication or sale of all or part of any of the repository collections is not permitted, except that material may be duplicated by you for your research use or educational purposes in electronic or print form. You must obtain permission for any other use. Electronic or print copies may not be offered, whether for sale or otherwise to anyone who is not an authorised user. 
This is the accepted version of the following article: DOCUMENTING NAPPING: The agentic force 1 of documents and human action, which has been published in final form at http://onlinelibrary.wiley.com/doi/10.1111/chso.2015.29.issue-3/issuetoc.

\section{DOCUMENTING NAPPING: The agentic force of documents and human action}

Maarit Alasuutari

Department of Education/Early Childhood Education

University of Jyväskylä

Acknowledgements:

The data the article draws on was collected in a project funded by the Academy of Finland (SA116272).

\section{Abstract}

The article examines the question of the agentic force of documents in institutional practices and proposes a conceptual model of the agentic relation between documentation and human actors. For this aim, it presents an empirical case study of Finnish early childhood education and care. The study deals with individual education plans (IEPs), which are an example of child documentation that aims at an individualized and participatory pedagogy. The analytical focus is on a single topic of an IEP, the child's afternoon naps, and how these are negotiated in the three-party encounter between a parent, a practitioner and the IEP document. The theoretical framework draws on the theories of documentality and institutional ethnography, on the analytic of government, and on the idea of domestication. The analysis applies the approach of discursive constructionism. By analysing the negotiations related to napping, the study demonstrates not only aspects of the agentic force of the IEP document, but also human resistance of it. 
This is the accepted version of the following article: DOCUMENTING NAPPING: The agentic force 2 of documents and human action, which has been published in final form at http://onlinelibrary.wiley.com/doi/10.1111/chso.2015.29.issue-3/issuetoc.

The articles in this issue provide illuminating examples of the increased interest and spread of child documentation in different childhood institutions. Children are narrated, assessed, measured, and visually recorded not just by professionals in childhood institutions but also by parents and the children themselves. Approaching this documentation from an agentic or active perspective means assuming that documentation can make a difference to the pre-existing state of affairs (Cooren, 2004). In other words, documentation has the power to influence notions about the child and childhood and thereby also to become consequential in children's lives.

If one is studying documents, per se, for example the construction of children in specific documents, the agentic approach can be seen as a fairly unproblematic framework for this purpose. However, when one is interested in the documentalized practices that involve both documents and human actors, one needs to rationalize how to relate and conceptualize the power of documents and human agency. As was described in the introduction to the special issue, this is a question to which different theories on documents/materiality and social life provide different answers, or which they do not specifically address (e.g. Barad, 2003; Ferraris, 2013; Latour, 1996, 2005; Smith, 2005). In this article I examine the question of the agentic force of documents in institutional practices and propose a conceptual model of the agentic relation between documentation and human actors. For this aim, I present an empirical case study of Finnish early childhood education and care (ECEC), or day care in the vernacular.

The study deals with individual education plans (IEPs), which are an example of child documentation that aims at an individualized and participatory pedagogy in early education (cf. Carr and Lee, 2012; Rinaldi, 2005; Rintakorpi and others, 2014). They are drafted for each child in Finnish day care in collaboration with the parent(s). 
This is the accepted version of the following article: DOCUMENTING NAPPING: The agentic force 3 of documents and human action, which has been published in final form at http://onlinelibrary.wiley.com/doi/10.1111/chso.2015.29.issue-3/issuetoc.

The data, drawn from a research project studying the function of IEPs in three day care centres in one Finnish municipality, comprise the IEP documents of 22 children and the voice-recorded and transcribed parent-practitioner discussions about these documents. The age of the children ranges between two and six years. The data were gathered in conformity with the ethical rules and principles of social scientific investigation (see Christians, 2000, pp. 138-140).

In the article I focus on a single (potential) topic of an IEP, the child's afternoon naps, and examine how these are negotiated in the three-party encounter between a parent, a practitioner and the IEP document. By restricting the focus to just one topic of the IEP facilitates a detailed analysis of the interaction process and the role of the document in it. Napping as a topic is again interesting, as it is a contradictory issue in Finnish ECEC. On the one hand, since the early days of public day care, it has been a routine institutional practice: after lunch children are expected to take a nap for about 1-2 hours (e.g. Korhonen, 1989). On the other hand, parents as well as children quite often complain about it (e.g. Alasuutari and others, 2014a). Indeed, napping can be defined as being in the border area between the private (family life) and public (early formal education), which can increase the tensions related to it. Here, I seek to show how napping, suggested to be a negotiable issue in the IEP document, becomes a non-negotiable topic in the discussion between the practitioner and the parent, and consequently, how the agentic force of the document is challenged.

Next, I introduce the theoretical framework of the study, followed by an examination of the ideals and regulations of the Finnish IEP practice. I then present an empirical analysis of the above-mentioned three-party interaction. The article 
This is the accepted version of the following article: DOCUMENTING NAPPING: The agentic force 4 of documents and human action, which has been published in final form at http://onlinelibrary.wiley.com/doi/10.1111/chso.2015.29.issue-3/issuetoc.

concludes with a discussion on the conceptual model of the agentic force of documentation.

Theoretical framework

The key concepts of this article are the document, documentation and documentalized practice. The document refers to textual, audio and visual records, in this case, of the child and her or his daily life. Depending on the context, documentation can mean either a generic compilation of documents, like legislation, or the process or event of creating a record or producing a document. Finally, documentalized practices are interactional encounters between documents and human actors. In the article, all the three concepts are related to institutions.

For the conceptual starting points, I draw on the theory of documentality by Maurizio Ferraris (2013) and on institutional ethnography as presented by Dorothy Smith (2005). The 'mentality' in the name of Ferraris' (2013) theory underlines the essential role that he argues documents have in society. He maintains that inscriptions - for example, documents, papers and archives - constitute a fundamental element in the social world and create social objects, such as childhood. According to the theory, institutions, such as early education, and institutional objects - including institutional actors such as children, practitioners and parents - are constructed by documents.

Ferraris only uses the term document in relation to institutions. Furthermore, he differentiates between strong and weak documents. Strong documents inscribe an act; weak documents mainly register issues. However, no document is strong or weak in itself, but has to be considered in its context. For Ferraris, the power of documents is 
This is the accepted version of the following article: DOCUMENTING NAPPING: The agentic force 5 of documents and human action, which has been published in final form at http://onlinelibrary.wiley.com/doi/10.1111/chso.2015.29.issue-3/issuetoc.

that of producing and fixing acts, making them available beyond the here-and-now, and making them transportable.

Dorothy Smith’s (2005) institutional ethnography has much in common with Ferraris' theory, but whereas Ferraris is concerned with documents, Smith uses the concept of text, referring to language that is materially replicable in words or images and can therefore transcend time and place. Like Ferraris, Smith sees texts as belonging to the distinctive forms of coordination that constitute institutions. On the one hand, her notion of text is agentic: she sees texts as active and as coordinating interindividual territory and, thus, as specifying what is social (for an institutional ethnographer). On the other hand, she states that texts are activated by their readers, and introduces the concept of text-reader conversation. The concept 'brings the text into action in the readers who activate it' (ibid., p. 105). The reader becomes the voice or agent of the text and at the same time interprets and acts from it in the specific context. Consequently, the agentic force of the text is also conceptualized as located in the human actor. For the present examination, Smith’s emphasis on the importance of examining texts in human action - as they 'enter and coordinate people's doings' (Smith, 2005, p. 170) - is important. This is an aspect that is not included in Ferraris's thinking (2013); he does not discuss the constitutive force of documents in relation to human agency.

Both Ferraris (2013) and Smith (2005) point to the essential linkage between documentation and power. For Smith, the basis of ruling relations is textual. Ferraris, again, states that 'governmentality' (Foucault, 1991) is possible because of documentality (Ferraris, 2013, p. 271). The linkage between documentation and power is also the starting point of this article. Following Foucault (2007), power is taken to be an issue that is always present in social life. It operates through 
This is the accepted version of the following article: DOCUMENTING NAPPING: The agentic force 6 of documents and human action, which has been published in final form at http://onlinelibrary.wiley.com/doi/10.1111/chso.2015.29.issue-3/issuetoc.

government, which refers to the striving to 'reach social and political ends by acting in a calculated manner upon the forces, activities and relations of the individuals that constitute the population' (Rose, 1999, pp. 4-5). In its functioning, government is dependent on knowledge of the population, which is produced in documentation, for example, in registerings and categorizations of individuals (Rose, 1999). From the perspective of documentality (Ferraris, 2013), documentation constitutes both the government with its dominant discourses or 'regimes of truth' (Foucault, 2007, p. 18), and the object of governance, the population and/or its individuals (cf. Kelle and others; Schulz, in this issue).

However, assuming the Foulcauldian notion of power in the present article also entails acknowledging the possibility of resistance to government. Since there is a constant movement across different practices of government, following controversial rationalities and discourses, there is always the possibility of opposition to a particular practice or to specific dominant discourses (Rose, 1996, p. 35).

Furthermore, government is not restricted to the borders of individual states (e.g. Foucault, 2007). For example, child documentation methods - and the dominant discourses they construct and are constructed from - spread transnationally, but not in any 'pure' form. One of the starting points of this article is therefore the concept of domestication. It refers to 'a transformation in which a reform process initiated by references to exogenous models, ideas or catchwords results in people viewing the outcome as a unique domestic creation’ (Alasuutari and Qadir, 2014, p. 9). This transformation can also be characterized as a field battle in which all kinds of counterdiscourses - or resistance in Foucauldian terms (e.g. Rose, 1996, p. 35) - are mobilized to defend the existing positions and interests and to negotiate the form that the reform will take. Therefore, the final outcome and the effects of the reform may 
This is the accepted version of the following article: DOCUMENTING NAPPING: The agentic force 7 of documents and human action, which has been published in final form at http://onlinelibrary.wiley.com/doi/10.1111/chso.2015.29.issue-3/issuetoc.

differ from what was originally planned (Alasuutari and Alasuutari, 2012). Moreover, the process of domestication is not restricted to any particular administrative field or hierarchy, but may take place in a number of fields. However, when considering the implementation of child documentation, the ultimate sites for the potential field battles, and for the resistance to the agentic force of documents, are the encounters between human actors and documents - the documentalized practices.

All the above-mentioned theories suggest that the phenomena commonly seen as being about an institution as a structural entity or understood as 'macro level' issues take their shape in everyday contexts and can be approached by studying those contexts. This understanding is in congruence with the framework of discursive constructionism (Potter and Hepburn, 2007), which comprises the methodological starting point of this article. Discursive constructionism examines talk and text in their institutional context. Thus, to approach the Finnish IEP discussions from this viewpoint we need to consider their institutional context, especially the national and municipal regulations guiding them.

Individual education plans in the national and municipal contexts

As mentioned earlier, drafting an IEP for a child is a universal practice in Finnish ECEC; it is not linked with special needs. As such, it is not an 'imported' practice or idea, but a unique invention, although not wholly detached from transnational trends (Alasuutari and Alasuutari, 2012). The IEP was first introduced in a governmental resolution in 2002 and described more specifically in the first national curriculum guidelines on ECEC a year later (see Stakes, 2004). As the term guidelines implies, the curriculum is not a statutory but a steering document. Its implementation has been 
This is the accepted version of the following article: DOCUMENTING NAPPING: The agentic force 8 of documents and human action, which has been published in final form at http://onlinelibrary.wiley.com/doi/10.1111/chso.2015.29.issue-3/issuetoc.

very successful, especially in introducing two new issues to Finnish ECEC: the idea of partnership and ECEC curricula/guidelines as a hierarchy consisting of municipal, unit-specific and individual curricula, that is, the IEP.

Nowadays, partnership is used as a general characterization of the parentteacher relationship in numerous municipal and unit-specific documents related to ECEC. It has become one of the dominant discourses of Finnish day care. According to the national guidelines, partnership means 'a conscious commitment by parents and staff to collaboration for supporting children's growth, development and learning' (Stakes, 2004, p. 28). Partnership is further described as requiring 'mutual trust and respect, and equality’ (ibid.). Moreover, parental knowledge is underlined. Although the guidelines do not explicitly describe how the partnership with parents should be implemented, they point to two contexts, in particular, for parental participation. These are the two most specific ECEC curricula introduced in the guidelines: the unitspecific curriculum, which parents 'should together be provided [with] an opportunity to influence' (Stakes, 2004, p. 29), and the IEP. According to the guidelines the IEP is drafted jointly with the child's parents and provides the basis for the child's education and care. It should take into account the individuality of the child and the parents' views in arranging the child's care. The national guidelines do not specify the content of an IEP, but give only a general description of it. However, the description projects a clear notion of individualized early education and care.

Although the guidelines are not a statutory document, they have been domesticated at the municipal level as if they were a binding regulation. This is shown in the comprehensive implementation of the IEP: in the majority of the municipalities it is drafted for almost all the children in day care (Säkkinen, 2010). In this sense, the guidelines can be defined as a strong document (Ferraris, 2013). 
This is the accepted version of the following article: DOCUMENTING NAPPING: The agentic force 9 of documents and human action, which has been published in final form at http://onlinelibrary.wiley.com/doi/10.1111/chso.2015.29.issue-3/issuetoc.

Almost all municipalities have implemented the guidelines by designing a local IEP

form, which frames the parent-teacher discussion and, when filled out, comprises the child's IEP. The forms exemplify and concretize the domestication of the notions of partnership and individualized early education and care in the municipal context. They assume specific duties and positions for parents and practitioners in the IEP discussion and suggest the topics to be covered in it (see Alasuutari and Karila, 2010; Alasuutari and others, 2014b, pp. 91-103; Karila and Alasuutari, 2012). For example, the focus of the following empirical examination, the child's napping, is not included in the IEP in every municipality (Alasuutari and Karila, 2010). However, the parentpractitioner meetings remain yet one more context in which the domestication of the IEP takes place.

Analysis of the three-party interaction in the IEP discussion

In two of the day care centres participating in the study, the IEP forms were identical, but in one setting the staff used an older version of the municipal IEP form. The older form did not have any questions about the child's daily care, and consequently, it did not have an entry or question about the child's napping. In the newer version of the form the entry was very simple: 'Napping/staying overnight in the setting' (The latter part of the entry was not relevant in the ECEC centres participating in the study, since they did not provide overnight care, as did some other settings in the municipality.) Otherwise, both versions of the form were very similar. They contained six or seven pages and included questions about family values and parenting practices (e.g. what is important in raising the child), about the child's development (e.g. social- emotional and language development etc.), and about the parent's expectations of ECEC (e.g. 
This is the accepted version of the following article: DOCUMENTING NAPPING: The agentic force10 of documents and human action, which has been published in final form at http://onlinelibrary.wiley.com/doi/10.1111/chso.2015.29.issue-3/issuetoc.

co-operation). They also included some questions for the child to answer (see

Alasuutari, 2014).

The differences in the documents can be seen as different domestications of the idea of partnership and the scope of individualized care. Where nap time is topicalized in the document, this implies that the child's sleeping can be negotiated individually and the parent can have a say in it. Where there is no entry, practices related to napping are constructed as not belonging to the sphere of individualized care and thus the parent-practitioner partnership.

Below, parent-practitioner discussions around both versions of the IEP forms have been analysed so as to remain open to different interpretations of the agentic force of documents. In the analysis, the interaction and the discourses that the talk draws on are examined. Here, discourse refers to a fairly coherent interpretative framework or rationalization that the participants apply to make sense of, and account for, the phenomenon or issue under discussion. The text on the IEPs is considered as turns at talk.

\section{Topicalizing napping time}

Before the parent and the practitioner met to discuss the child's IEP, the parent was expected to fill in (parts of) the IEP form at home and then bring it back to the ECEC centre so that the practitioners could go through it before one of them had the meeting with the parent(s). The instructions on the form tell the parents to fill it in 'according to their views about day care and their wishes concerning it'. The text also states that the education and care practices will be agreed in the meeting with the practitioner. 
This is the accepted version of the following article: DOCUMENTING NAPPING: The agentic force1 of documents and human action, which has been published in final form at http://onlinelibrary.wiley.com/doi/10.1111/chso.2015.29.issue-3/issuetoc.

Hence, the IEP form suggests that the parent-practitioner discussion means a negotiation about the child's early education.

In the present data, the entry about napping has usually been responded (see Table 1). In most cases the parent has written the answer, but in one case the practitioner has recorded the main points of the IEP discussion.

\section{ADD TABLE 1 SOMEWHERE HERE}

The parents' responses show two kinds of orientations to the answering. Most often they have responded to the entry as if it might be an interview question about the child's sleeping habits or about the child's need for rest in general. Consequently, on the document they have written down their perspective on the child's sleeping at home. (The one response written by the practitioner also shows the same orientation.) Below are two examples of this type of responses:

'At home no naps.'

'If Joanna is sleepy, she usually easily falls asleep.'

It is only in a couple of cases that the responses express the parent's expectations or suggestions regarding napping in day care. As in the following example, the parents are, however, careful in phrasing their expectations.

'A good thing, as a relaxing moment. 
This is the accepted version of the following article: DOCUMENTING NAPPING: The agentic force 2 of documents and human action, which has been published in final form at http://onlinelibrary.wiley.com/doi/10.1111/chso.2015.29.issue-3/issuetoc.

The example can be read as suggesting that the child would not need to fall asleep during the nap time, but that she/he could just relax. However, this is not presented as an explicit demand or expectation of ECEC. This kind of considerate parental communication is evident throughout the data, including the actual IEP discussions as will be shown later. Such considerate communication illuminates how the parents, for their part, assume and reproduce an asymmetrical relationship to day care and its professionals (cf. Alasuutari, 2010; Hughes and MacNaughton, 2000).

In the interaction proper, the IEP document has a strong position in prescribing the topics that are talked about and their order. Both parents and practitioners orient to the order of the document from start to finish. Consequently, the IEP document becomes agentic in influencing the topics of talk and it also has the first turn at talk in the episodes, including those discussing nap time. However, as Smith (2005) states, a text needs a human agent to voice it. This role is most often assumed by the practitioners. They usually introduce the topic of napping by repeating the beginning part of the entry: 'Then the nap time'. After this they often say something about the child’s napping habits in day care. Some practitioners also ask the parent about the child’s sleeping habits. In just four cases (out of 15), the practitioner referred to the parent's response either by reading it from the document or by explicitly commenting on it.

Thus, the entry about napping on the IEP form is agentic in introducing the topic, but the text written as a response to it is not usually topicalized. Instead, the practitioners take the lead in the interaction and proceed either by informing the parent of their observations of the child's napping or by interviewing the parent about the child's sleeping habits. 
This is the accepted version of the following article: DOCUMENTING NAPPING: The agentic force3 of documents and human action, which has been published in final form at http://onlinelibrary.wiley.com/doi/10.1111/chso.2015.29.issue-3/issuetoc.

The child's sleeping habits are also often discussed in cases, where they have not been addressed in the IEP form (see Table 1). In these cases, they become topical in relation to other questions or entries on the IEP form, for example, to questions addressed to the child about things he/she does not like in day care. Moreover, in these cases an element of concern is often implied about the child's sleeping habits (for example, the child's unwillingness to take a nap in ECEC).

Regardless of how the child's napping and sleeping become topicalized, two dominant discourses are (nevertheless) applied in the interaction: the naturalized discourse of napping and the discourse of a problem with/in the child. As a function of these discourses, a negotiation about practices related to the child's napping becomes 'unnecessary' in the interaction. Hence, they provide for the human actors the main resources with which to resist the power of the IEP document.

\section{Naturalized discourse of napping}

The naturalized discourse of napping refers to talk in which the child's falling asleep during the nap time is taken for granted. The fact that falling asleep is assumed and expected of children, is shown, among other things, in the praise that the practitioners express when a child fulfils this expectation. The discourse is also evident in the accounts about children whose conduct diverges from what is expected, a topic to be discussed in the next section. In the following extract the practitioner gives credit to three-year-old Hanna regarding her sleeping. (The transcription symbols are explained in the appendix.) 
This is the accepted version of the following article: DOCUMENTING NAPPING: The agentic force 4 of documents and human action, which has been published in final form at http://onlinelibrary.wiley.com/doi/10.1111/chso.2015.29.issue-3/issuetoc.

T: Really nicely she has (.) also fallen asleep (.) here like (.) I just said that since (.) I ... have one child I stroke there (.) for a quite long time (.) then the other one (refers to Hanna) already wants me to come and tuck her in and so on but it is again such a sensitive situation (with the other child) that (...) it might be that Hanna already falls asleep before I (.) have time to tuck her in

The practitioner's description implies that Hanna falls asleep without any special attention from the staff. She gives a positive characterization, 'nicely', about this. Although she indicates that she might like to tuck Hanna in if she had time for it, her description about stroking the other child also suggests that stroking is extra and done for special reasons. In the data, it is common that the practitioners talk about stroking as something that needs to be done to calm a particular child down, and thus to keep order in the room. Consequently, the ideal child is the one who 'just' falls asleep on her/his own, like Hanna does.

The naturalized discourse of napping occupies such a strong position in the discussions that the talk about a child taking a nap does not seem to need any justifications or explanations at all. Sometimes there are references to the diminishing need for napping with maturation. Although the parent and/or the practitioner might imply that the child is 'growing' out of napping, in none of the discussions does the potential need to change or individualize napping practices become topical. Instead, keeping the practices the same is usually justified either by the child's early arrival at the day care centre or by issues related to the children as a group, as in the extract below, in which the practitioner talks about a group (class) of 5- to 6-year-olds.

P: And our group surely (.) £needs£ (refers to napping) 
This is the accepted version of the following article: DOCUMENTING NAPPING: The agentic force 5 of documents and human action, which has been published in final form at http://onlinelibrary.wiley.com/doi/10.1111/chso.2015.29.issue-3/issuetoc.

M: $£$ Yeah£

P: $£$ the $£($.$) noise and coming and going (.) you can clearly see$

M: [Yeah

P: [that they (the children) are exhausted

The practitioner's statement ends an episode in which the mother has both aligned with the practitioner's interpretation of her son needing the afternoon nap and stated that he does not always take a nap at home and that he has started to have difficulty in falling asleep in the evening. There is a tension implicit in the discussion. By her generalized (and professional) statement about children, the practitioner closes the discussion on the topic and avoids addressing the contradictory implications of what the mother has said. The mother shows (seeming) alignment with the practitioner's statement in her minimal feedbacks ('yeah') and in her use of a smiley voice (see Alasuutari, 2009). At the same time, she conforms to, and co-constructs, her asymmetrical relationship with the practitioner. As a result, both parties participate in resisting the agentic force of the IEP document and its idea of individualized care. The leading role in this process is taken by the practitioner, but the parent complies with it, even when she has presented ideas that could challenge the practices regarding napping in ECEC. Overall, it is frequent in the present data that the parent and the practitioner seem to agree about the end result of the discussion regardless of the (implicit) tensions contained within it. 
This is the accepted version of the following article: DOCUMENTING NAPPING: The agentic force 6 of documents and human action, which has been published in final form at http://onlinelibrary.wiley.com/doi/10.1111/chso.2015.29.issue-3/issuetoc.

The data also include descriptions of the child's conduct that do not fit the naturalized discourse of napping. They are commonly indicative of a difficulty. In these episodes, the accounts of the situation are based on rationalizations that focus on the child. Daycare practices are not taken up as a potential explanation for the difficulties of this kind.

The discourse in question comprises two different notions of the child. First, the child is viewed as intentionally doing something that prevents her/him falling asleep. The next extract exemplifies this notion. Before the quoted episode, the mother (who herself is a professional in ECEC) has said that her child does not complain about the nap time as much as he used to do. The mother has also described the practices by which she tries to follow similar napping time routines at home as those practised in the day care centre. On the whole, she depicts her son as having a 'no'-period. The practitioner then describes the situation in day care.

P: Well there has been a little restlessness in bed like (he) has to get up (.) and look around to see what the others are doing but

M: That's what he does at home too

P: Okay

M: A dumbo Ereally£

P: Yeah

The practitioner is careful in formulating what she says: in her talk she does not clearly define the child as intentionally monitoring others when he should be asleep. Her phrasing 'has to' can be understood as referring to an intentional behaviour by the child, but also to a psychological force inside the child. In her response the mother 
This is the accepted version of the following article: DOCUMENTING NAPPING: The agentic force 7 of documents and human action, which has been published in final form at http://onlinelibrary.wiley.com/doi/10.1111/chso.2015.29.issue-3/issuetoc.

chooses the former understanding when labelling her son as a 'dumbo': the child's

behaviour becomes defined as intentional and explained by his stupidity (see

Alasuutari and Markström, 2011, p. cf. ).

Second, difficulties concerning napping are associated with the child's psychological state and well-being. In these descriptions the child's behaviour is not seen as intentional. The assumption is that there is something 'inside' the child that causes her/him not to fall asleep. It might be a skill-related issue, such as not possessing the ability to calm down. The explanations may also be linked with the child's mental wellbeing. Below, a practitioner associates the variation witnessed in a six-year-old's napping with a period of anxiety that the child has just experienced according to both the parents and the practitioner.

P: But actually you can also see that the (.) period is now over (.) like (.) from the fact (.) that he has now slept on two (consecutive) days he slept yesterday and (...) the previous day he slept but before that he has been anxious (in bed) (.) he has followed the adult with his eyes all the time and he has been up there (in his bed) (...) he has been like anxious ... but now it is like passing

Before the quoted extract the parents and the practitioner were discussing the child's complaints about attending day care. The child's behaviour is described as reflecting a (developmental) phase of anxiety, which seems to be passing. The fact that the child has not slept during every nap time is interpreted as a sign of illbeing. In this context, the opposite - that is, napping - becomes a sign of a healthy child. The question of whether napping practices should be changed is not considered. 
This is the accepted version of the following article: DOCUMENTING NAPPING: The agentic force 8 of documents and human action, which has been published in final form at http://onlinelibrary.wiley.com/doi/10.1111/chso.2015.29.issue-3/issuetoc.

When the child's behaviour challenges the naturalized discourse of napping and day-care napping practices, individualized rationalizations about the child being difficult or having difficulties provide an effective resource to resist the suggestion, contained in the IEP document, to negotiate the day-care centre’s napping practices. Again, the discourse is co-constructed by the practitioner and parent. The parents may either openly support the discourse or comply with the practitioner's accounts less overt way, if these seem to run counter to what they have said or implied in their talk.

\section{Conclusion}

This article reports on a case study in the area of Finnish ECEC. Negotiations on the topic of the child's afternoon nap, arising in the course of going through the form to be used when drafting the child's IEP, were studied in in parent-practitioner meetings in a Finnish municipality. The IEP is an example of child documentation that has become increasingly common in ECEC. The starting point of the article was the assumption that documents have constitutive force, and hence power to shape institutional practices, objects and actors (Ferraris, 2013; Smith, 2005). The article also drew on the theory of domestication (Alasuutari and Qadir, 2014). It proposes that as a result of a field battle or resistance - that is, aims to defend existing positions and interests - new models and ideas go through a transformation process during their implementation. Therefore, the expected reform can take unexpected forms. By analysing the negotiations related to napping, the study demonstrated not only aspects of the agentic force of the IEP document, but also human resistance of it.

The agentic force of the IEP form was evident in the way it structured the parent-practitioner discussion and defined its agendas. On the whole, the IEP form 
This is the accepted version of the following article: DOCUMENTING NAPPING: The agentic force 9 of documents and human action, which has been published in final form at http://onlinelibrary.wiley.com/doi/10.1111/chso.2015.29.issue-3/issuetoc.

was 'strong' (see Ferraris, 2013) in the sense that it had the power to topicalize the issues discussed and to invite the participants to register/write down their responses on the form. However, the IEP form also seemed to be a 'weak document' (ibid.), at least regarding its implications for negotiating napping practices in ECEC, since no such negotiations were actualised (cf. Alasuutari, 2014). Instead, the analysis showed how both practitioners and parents resisted these implications by drawing on a naturalized discourse of napping and on a discourse that defined the child as problematic or as having internal deficiencies, when he or she did not fall asleep as expected. Moreover, the analysis demonstrated how latent asymmetry between the parent and the practitioner was produced in the interaction, where the practitioner was positioned as more dominant in resisting the suggestions of the IEP form. From the results of this case study and the contextualization of the practice of IEP at the national and municipal level, it is possible to infer the following conceptualization and model of the agentic force of documents (see Model 1).

The model differentiates between two contexts of documentation: documentalized practices and public documentation. The two are not separate from each other but interdependent. Public documentation would not exist without documentalized practices, and practices would not exist without public documentation. The meeting point of the two contexts of documentation is the domestication that takes place at their boundary (cf. Alasuutari and Qadir, 2014): that is, when public documentation becomes involved in documentalized practices.

The concept of a documentalized practice refers to institutional functions that are carried out with different forms of documentation. In short, documentalized practices are interactional encounters between human actors and documents that are a product of, and belong to, public documentation, but also produce it. The case study 
This is the accepted version of the following article: DOCUMENTING NAPPING: The agentic force 20 of documents and human action, which has been published in final form at http://onlinelibrary.wiley.com/doi/10.1111/chso.2015.29.issue-3/issuetoc.

exemplified how the documentalized practice of the IEP discussion, using the local

IEP form as its starting point, produced a new piece of public documentation, the child’s education plan, as the parent and practitioner filled in the IEP form.

Public documentation refers to texts (cf. Smith, 2005), in the institutional domain. Such texts, including reports, stipulations, guidelines, statistics, forms, and questionnaires, may be stored in several ways, from hard copies to digital or other electronic form. Public documentation is not, however, always open to everyone, for example client records in social work. However, it is public in the sense that it is always partly institutionally governed.

Public documentation is produced at all levels of social life. In the present study, the IEP form is an example of public documentation drafted at the local level (in the municipality). However, its implementation is guided by documentation at the national level (e.g. the curriculum guidelines of ECEC). Moreover, its development is linked with public documentation at the international level through collaboration within the Organization for Economic Cooperation and Development (Alasuutari and Alasuutari, 2012).

In society, public documentation has many functions: it constructs organizations, institutions and government; creates norms and regulations; produces discourses, categorizations and ideas; constitutes and records practices. Commonly, a documentalized practice is like a junction of public documentation, and hence, a point at which various discourses, ideas, constraints and possibilities meet. Different discourses prescribe and presume different subject positions for those included in the practice. For example, in the present study the public documentation guiding the IEP practice and the municipal IEP forms drew on a discourse of parent-practitioner partnership, with an emphasis on equality and parental knowledge (see Stakes, 2004). 
This is the accepted version of the following article: DOCUMENTING NAPPING: The agentic force1 of documents and human action, which has been published in final form at http://onlinelibrary.wiley.com/doi/10.1111/chso.2015.29.issue-3/issuetoc.

However, in the IEP discussion the parents and the practitioners seemed mainly to

follow the more traditional discourse of a professional hierarchy. This exemplifies

how the process of domestication (often) constitutes a field battle of different

discourses and how in this process human resistance has the power to overcome the agentic force of documentation. The end result of the domestication process also illuminates in what sense a particular documentation can be considered as strong or weak.

In sum, the case study presented here and the conceptualization based on it suggest that more attention should be paid to the documentalized practices at the grass-roots level when developing and implementing child documentation in different services. However, the model described above remains tentative and needs to be further researched and developed.

Appendix: Transcription symbols

P practitioner

M mother

(.) a pause

$£$ the use of smiley voice

[ the start of overlapping talk

(...) parts of the talk left out (names, repetition, etc.)

(in bed) verbal description or explanation

All names are pseudonyms. 
This is the accepted version of the following article: DOCUMENTING NAPPING: The agentic force22 of documents and human action, which has been published in final form at http://onlinelibrary.wiley.com/doi/10.1111/chso.2015.29.issue-3/issuetoc.

References:

Alasuutari M. 2009. What is so funny about children? Laughter in parent-practitioner interaction. International Journal of Early Years Education 17: 105-118.

Alasuutari M. 2010. Striving at Partnership: Parent-Practitioner Relationships in Finnish Early Educators' Talk. European Early Childhood Education Research Journal 18: 148-161.

Alasuutari M. 2014. Voicing the child? A case study in Finnish early childhood education. Childhood 21: 242-259. DOI:10.1177/0907568213490205

Alasuutari M, Karila K. 2010. Framing the Picture of the Child. Children \& Society 24: 100-111.

Alasuutari M, Karila K, Alila K, Eskelinen M. 2014a. Vaikuta varhaiskasvatukseen. Lasten ja vanhempien kuuleminen osana varhaiskasvatuksen lainsäädäntöprosessia [Have a say about early childhood education and care. Listening to children and parents in the legislative process of early childhood education and care]. Opetus- ja kulttuuriministeriön työryhmämuistioita ja selvityksiä 13. Ministry of Education and Culture: Helsinki.

Alasuutari M, Markström A-M. 2011. The Making of the Ordinary Child in Preschool. Scandinavian Journal of Educational Research 55: 517-535.

Alasuutari M, Markström A-M, Vallberg-Roth A-C. 2014b. Assessment and Documentation in Early Childhood Education. Routledge: London and New York.

Alasuutari P, Alasuutari M. 2012. The domestication of early childhood education plans in Finland. Global Social Policy 12: 129-148.

Alasuutari P, Qadir A. 2014. Introduction. In Alasuutari P, Quadir A (Eds.), National Policymaking: Domestication of Global Trends. Routledge: London; 1-22/

Barad KM. 2003. Posthumanist Performativity: Toward an Understanding of How Matter Comes to Matter. Signs: Journal of Women in Culture and Society 28: 801831.

Carr M, Lee W. 2012. Learning Stories. Constructing Learner Identities in Early Education. SAGE: Los Angeles, London.

Cooren F. 2004. Textual Agency: How Texts Do Things in Organizational Settings. Organization 11: 373-393. DOI:10.1177/1350508404041998

Ferraris M. 2013. Documentality: Why It Is Necessary to Leave Traces. Fordham University Press: New York.

Foucault M. 1991. Governmentality. In Burchell G, Gordon C, Miller P (Eds.), The Foucault Effect: Studies in Governmentality. University of Chicago Press: Chicago; 87-104/ 
This is the accepted version of the following article: DOCUMENTING NAPPING: The agentic force3 of documents and human action, which has been published in final form at http://onlinelibrary.wiley.com/doi/10.1111/chso.2015.29.issue-3/issuetoc.

Foucault M. 2007. Security, territory, population: Lectures at the College de France, 1977-78. Palgrave Macmillan: Basingstoke.

Hughes P, MacNaughton G. 2000. Consensus, Dissensus or Community. The Politics of Parent Involvement in Early Childhood Education. Contemporary Issues in Early Childhood 1: 241-258.

Karila K, Alasuutari M. 2012. Drawing Partnership on Paper: How do the Forms for Individual Educational Plans prescribe Parent-Teacher Relationship? International Journal about Parents in Education 6: 15-27.

Korhonen M. 1989. Käytäntösokki. Tutkimus päiväkodin toimintatavan muutoksesta. Vastapaino: Tampere.

Latour B. 1996. On Interobjectivity. Mind, Culture, and Activity 3: 228-245.

Latour B. 2005. Reassembling the Social: An Introduction to Actor-Network-Theory. Oxford University Press: Oxford.

Potter J, Hepburn A. 2007. Discursive Constructionism. In Holstein J A, Gubrium J F (Eds.), Handbook of Construtionist Research. The Guilford Press: New York; 275293/

Rinaldi C. 2005. Documentation and assessment: what is the relationship? In Clark A, Kjørholt A T, Moss P (Eds.), Beyond Listening. Children's Perspectives on Early Childhood Services. The Policy Press: Bristol, UK; 17-28.

Rintakorpi K, Lipponen L, Reunamo J. 2014. Documenting with parents and toddlers: a Finnish case study. Early Years 34: 188-197. DOI:10.1080/09575146.2014.903233

Rose N. 1996. Inventing Our Selves: Psychology, Power, and Personhood. Cambridge University Press: Cambridge, England ; New York.

Rose N. 1999. Governing the Soul: The Shaping of the Private Self. Free Association Press: London.

Smith DE. 2005. Institutional Ethnography: A Sociology for People. AltaMira Press: Lanham.

Stakes. 2004. National Curriculum Guidelines on Early Childhood and Care in Finland: Helsinki.

Säkkinen S. 2010. Lasten päivähoito 2010 - Kuntakyselyn osaraportti. National Institute for Welfare and Health: Helsinki. 